\title{
Analysis on the Application of Innovative Thinking in the Design of Men's Wear
}

\author{
Zhexin Liu \\ Zhuhai College of Jilin University \\ Zhuhai, China
}

\author{
Bing Han \\ Zhuhai Nanping Middle School \\ Zhuhai, China
}

\begin{abstract}
Innovative thinking is the soul of design. As for the relatively stylized design of men's wear, innovative thinking is indispensible and important. This thesis makes deep study on the design of men's wear from the perspective of innovation. Based on the analysis of the necessity of applying innovative thinking into the design of men's wear, this thesis also illustrates the characteristics of innovative thinking in the design of men's wear, and employs examples to prove the using of innovative thinking in the design of men's wear, and proposes the development approach of innovative thinking in the design of men's wear.
\end{abstract}

Keywords-design of men's wear; innovative thinking; application

\section{INTRODUCTION}

The design of garment can reflect the designer's ingenuity, as well as the aesthetic characteristics of the era. As the representation of fashion and the symbol of advance guard, the design process of the fashionable cloth needs innovative consciousness and innovative thinking much more. As one of the important part of clothing design, the design of men's wear is relatively conservative compared with women's wear, lacking the bold innovation consciousness. Therefore, the traditional men's wear and the present professional men's wear have small difference from the material to the style. And thus, innovative thinking should be added to the relatively conservative design of men's wear, and keep trying to use the color and design elements of women's wear into the design of men's wear to fulfill the "outmoded conventions" of the design of men's wear.

\section{THE NECESSITY OF INNOVATIVE THINKING IN THE DESIGN OF MEN'S WEAR}

\section{A. Inevitable Requirement of Meeting Men's Pursuit to Variety}

In the public men's wear sales market, the integrated design style of men's wear has no sense of novelty. The color of gray and dark, the old and simple match, and the stereotyped design cannot meet modern men's pursuit of clothing. In daily life, many men tend to be different and special, representing their characters through clothing and highlighting themselves. However, the traditional clothing design "valued women over men", resulting to the lack of enough wide space for men to choose their clothing. However, need is the priority of the market. The innovation of men's wear is advanced continuously because of the increasing needs, and thus much more importance was taken on the application of innovative design and innovative thinking in men's wear, which gradually reflected in the design of men's wear.

\section{B. Satisfy the Sales Market Development of Men's Wear}

The design of men's wear is to realize the use value of the clothing and the commodity value. The sales amount is the standard of whether the design is good or not. As the same with women's wear, men's wear also needs to be changed according to the tide of the times and the aesthetics of men. Therefore, the design of men's wear should always meet the needs of market development, adapt to the times, satisfy the public aesthetics, or directly lead to developing trend of men's wear. However, the realization of these requires the bold innovation on the design of men's wear. As a result, the innovative thinking in the design of men's wear is a design concept that must be absorbed in order to meet the needs of the development of the times and the requirements of the sales market.

\section{Essential Requirement to Meet Men's Psychological Needs}

Along with the social development, men have played different roles in the society, and their needs to clothing are various respectively. The monotonous design style and the nearly same color match cannot meet men's psychological needs for beauty, individuality and professional representation. At the same time, "loving the new and hate the old", and "advocate individuality" have become the pursuit of more and more healthy and fashionable men. No doubt that clothing is the most direct representation of their psychological characters. Therefore, add innovative thinking and innovative consciousness in the design of men's wear can reflect men's psychological character and the professional pursuit.

\section{ANALYSIS ON THE APPLICATION OF INNOVATIVE THINKING IN THE DESIGN OF MEN'S WEAR}

\section{A. Characteristic of Innovative Thinking in the Design of Men's Wear}

In different industry, innovative thinking has different representation. In the design of men's wear, the innovative thinking has the following characteristics. 
1) Novelty: Innovation is firstly represented in "new". In the design of men's wear, innovation is a novel, special and unconventional representation. Innovative thinking requires that the process of the design of men's wear cannot be done in the original thinking mode, design ways and mode, but to make bold innovation on the traditional men's wear or the popular clothing from a novel angle, aiming to design the cloth that captures people's eyes. For example, men's wear tends to be more neutral at present, and many men like fashionable and light clothing. Therefore, many designers apply the thick sweater material and bright color to embellish the collar and other important parts of men's wear or to change the overall match "Fig. 1", creating many classic examples of innovative design of men's wear.

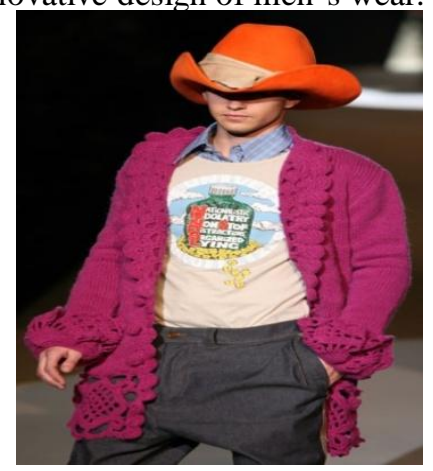

Fig. 1. Bright and thick sweater match

2) Uniqueness: One feature of innovation is uniqueness. In the design of men's wear, innovation should be special, initiative and unique, leading the fashion of men's clothing through innovative thinking. That is to say, the innovation of the design of men's wear should be reflected in its uniqueness, which is not a slight change to the clothing, but create a special design type or way on men's clothing by the innovative thinking. For example, lace is commonly used in women's formal dress and wedding dress, and it is also used in the clothing design of the noble class in western countries, but it is rarely used in the design of men's wear in China. However, in recent years, lace has been used in the design of men's wear and developed fast along with the bold innovation of the design of men's wear. Lace stitching and lace jacquard can be found in the design of men' shirt, formal dress and underwear "Fig. 2" and "Fig. 3", which greatly increase the fashion sense and sexy element of men's clothing.

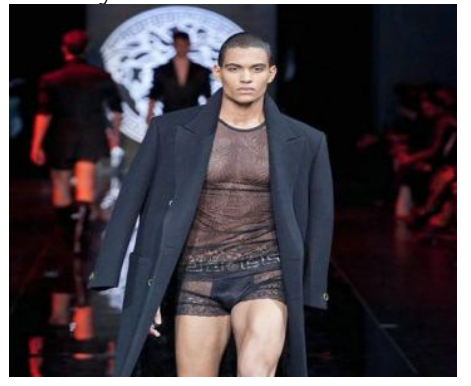

Fig. 2. The use of lace in underwear

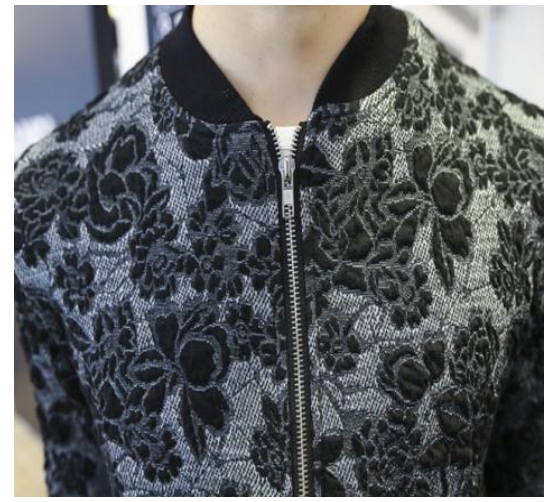

Fig. 3. The use of lace in men's upper garment

3) Flexibility: Flexibility in the design of men's wear means no conventionality and unconformity. The clothing design can be in an unrestrained and vigorous style without any ideological bondage, breaking the restraints of the previous design mode, boldly and flexibly design men's wear in material, color, match and so on. By breaking the stereotyped mode and design style, innovative thinking promotes the multi-angle, multi-layer and multi-direction development trend in the design of men's wear. Through the application of innovative thinking, the designer effectively integrates things that cannot be combined or with no relationship to serve for the design of men's wear, forming a new representing mode in the design of men's wear. Following the trend of Punk Movement, the designer catches people's thinking of following the trend and their consciousness of imitation, and thus designs "rag look" punk clothing, also known as "beggar clothing", which greatly changed people's fixed opinion towards the beauty of clothing and redefined people's aesthetics towards clothing.

\section{B. Manifestation of Innovative Thinking in the Design of Men's Wear}

Due to the characteristics of novelty, uniqueness and flexibility, innovative thinking in the design of men's wear plays the role of leading the trend and giving prominence to the fashionable features, which is indispensible. As for the innovative thinking type in the design of men's wear, it is mainly divided into divergent thinking (horizontal, vertical, and lateral and reversal), convergent thinking, imagery thinking and so on, which are manifested in.

1) Divergent thinking: Divergent thinking is the basic type and requirement in human innovation. In the design of men's wear, divergent thinking is also the most important type of innovative thinking. It refers to the multi-directional reflection after receiving the information stimulation, which is not restricted by time and space, or the original thinking mode and design concept. This kind of thinking ways doesn't stick to the old thinking framework and break the present thinking mode. Divergent thinking can be classified into horizontal, vertical, and lateral and reversal thinking. 
- First, horizontal thinking in the design of men's wear is a kind of horizontal transfer of the design ways, that is to say, after being inspired by the excellent fruits in other fields, incorporate the corresponding design inspiration into the design of men's wear in time, and promote the innovation of the design. For example, in recent years, the price of blue-and-white porcelain is soar in the collection market, which started the advocating of pattern of blue-and-white porcelain. The design concept flow with this trend and be best represented in the design of men and women's clothing. The typical representative of this horizontal thinking can be seen from the blue-and-white pattern clothing wear by Ms. Peng Liyuan during her visit to other countries and the vintage pattern of blue-andwhite porcelain men's clothing sold crazily online "Fig. 4".

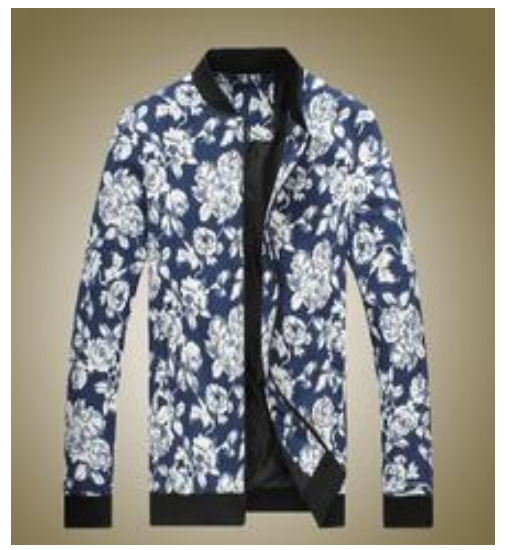

Fig. 4. Elements of blue-and-white porcelain in the design of men's wear

- Second is the vertical thinking. The development of things is the variable on time, and thus we usually explore the developing rules of things according to the time sequence. Vertical thinking is also a kind of thinking mode formed by the time sequential rules, analyzing the past, basing on the present and exploring the future according to the past, present and future of things. The design of men's wear also has distinctive time feature. What was considered to be ugly becomes the leading fashion of the present; what was considered to be informal men clothing becomes the most popular style in the recent fashion field. At the same time, the fashionable clothing at present may also be out-dated in the near future, and the popular clothing may be the name of outdate. The designer should try their best to consider the design of men's wear relying on the future developing trend of fashion and design based on the present and looking to the future, and jumping out of all the set thinking restrictions of the times, and thus realize leading the developing trend of men's wear by vertical innovation.

- Third is the lateral thinking. In the design of men's wear, lateral thinking refers to that the designer diverge from the positive thinking channel and seek for the breakthrough on the design of men's wear from a side view, aiming to the obvious development in the design to revolute the normal design from the shackle of thinking set and achieve changes in the design concept. For example, many world famous designers use non-conventional materials to design men's clothing instead of the design norm, and gain considerable fame in the design of men's wear for a long time. In addition to realize the innovation effect, it also expands the design concept and thinking of the designer.

- Fourth is reverse thinking, which means using reverse thinking way to redefine men's clothing opposite to the normal thinking, making bold innovation on the dressing and design and creating unconventional design and wearing style in men's clothing. It may be very popular in the fashion field, or being criticized by the public. For example, men skirt has completely broken the bondage of men's sex and dress tradition. By employing the design that is opposite to the tradition and positive design concept, the designer expresses his design concept and non-conventional design ways. The design of men's skirt changed the traditional design concept, and adapted men's trousers "Fig. 5" according to women's skirt.

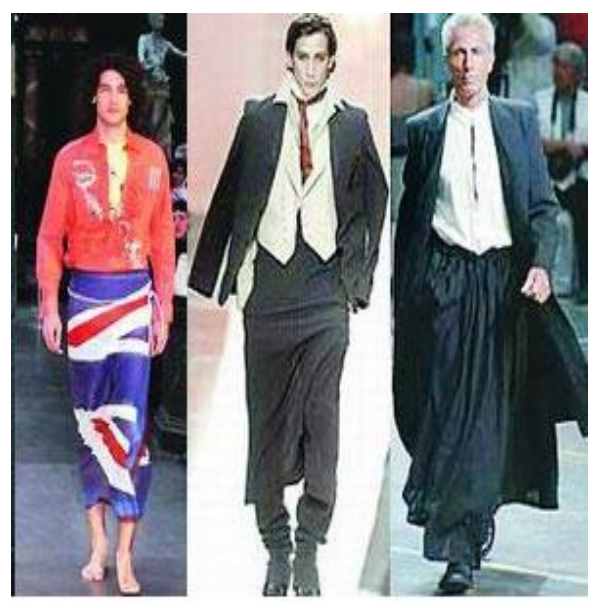

Fig. 5. Men's skirt is the representation of reverse thinking

2) Convergent thinking: Compared with divergent thinking, convergent thinking gathers all kinds of external information together and makes breakthrough in a certain aspect. As in the design of men's wear, convergent thinking means selecting a major part in the design to make the breakthrough, such as the shirt, trousers, upper wear, and waistcoat and so on. For example, in the design of suit, the "Korean Style" "Fig. 6" of lighting and thinning, tight and simplified for the coat of suit and the slim cut jeans are the examples of concentrating on a certain aspect to make detailed research and careful design to realize the various design of clothing, and thus satisfy the multi needs of the customers. 


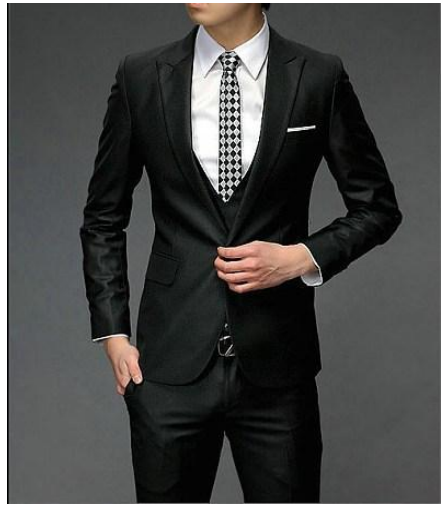

Fig. 6. Korean style suit

3) Imagery thinking: Imagery thinking is the thinking activity that relying on the image of a certain thing in one's mind, analyze, abstract and conclude the image and finally illustrate it. This kind of thinking is more basic compared with other innovative type. Therefore, it has been widely used in the design of men's wear for a very long time. The clothing designer forms a complete generalization and image feature in his mind according to his recognition and understanding of things in real life, and then transfer these images and features into clothing through the design method. For example, the leopard print clothing, fur clothing, flower pattern clothing in men's wear, etc.. "Fig. 7", "Fig. 8"

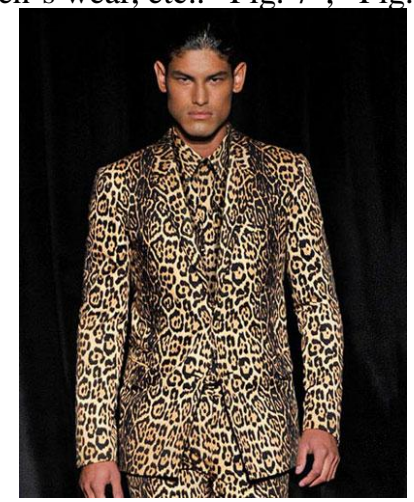

Fig. 7. Leopard print clothing

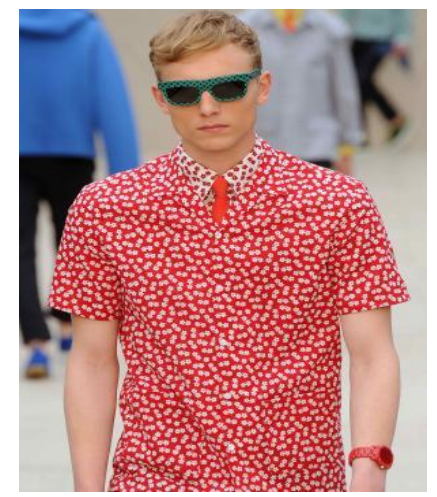

Fig. 8. Flower pattern clothing

\section{Cultivation Of InNovative Thinking In The DESIGN OF MEN'S WEAR}

\section{A. Increasing Knowledge Accumulation}

There is very strict requirement for men's clothing designer. It requires the designer not only continue his study and accumulate knowledge, but also seek the innovative thinking mode based on the present knowledge. The accumulation of knowledge is a process from quantitative changes to qualitative changes. When the accumulation is in a relatively low level, the designer is only in the imitation stage, or blind imitation stage, because he cannot engage in the practical research of the design of men's wear under the condition that he is not familiar with the basic design theory. Therefore, lay sound theoretical foundation and realize qualitative changes in the process of quantative accumulation, and thus acquire the basic innovative thinking ways to conduct innovative research on the design.

\section{B. Improving Art Accomplishment}

Clothing design is a design art, therefore, it requires certain art accomplishment and art design skill. As the designer of men's wear, he should has a thorough understanding of on the design of men's wear, but also has to make active innovation in the formation, color match, material and detail, and form his own special opinion. This not only require the designer to improve his artistic understanding through the reading of artistic data and participate in all kinds of craft art exhibition activities, improving his aesthetics, actively absorbing inspiration into creation, and seeking lateral transformation during the design. In addition, he should also continuously conduct artistic design practice to improve his art design ability and manifestation ability.

\section{Strengthening Perception of Life}

Innovative thinking comes from life and is higher than life, from life and goes back to life. Thus, it requires the designer to pursue beauty, explore beauty and sense beauty based on life. As a kind of artistic representative, the design of men's wear comes from the psychological activity and creating concept, but also from the daily life. The designer should go deep into the front line of life to sense the living condition and psychological needs of all social classes, and then go to find the true valued things after his heart being baptized by social practice and undergone the changes of the society. Only in this way can he create the designing work that meets the public demands and has the design specialty, as well as to reflects the truest side of the public.

\section{Stressing the Pursuit to Beauty}

The design process of men's wear is the process of seeking beauty. Therefore, the men's wear designers should always find beauty, sense beauty and pursue beauty in the daily life. He should realize that the pursuit to beauty is endless, especially in clothing design. He should find the external beauty and image beauty through different thinking mode based on the design of men's wear, dig internal beauty continuously by innovative thinking, create and demonstrate beauty through various design methods. 


\section{CONCLUSION}

To sum up, in the design of men's wear, innovative thinking has the characteristics of uniqueness, novelty, flexibility and so on. In the specific design process, innovative thinking mainly manifested in divergent thinking, convergent thinking, imagery thinking and so on, and is widely accepted and continually developed in the design process of men's wear. In a word, innovation is the soul of men's wear, and the design of men's wear cannot do without innovative thinking. Only pushing by the new way of thinking, men's wear can blaze new trails in a pioneering spirit and lead the fashion trend, as well as adapt to the development trend of the sales market and meet the various professional and psychological needs of men.

\section{ACKNOWLEDGMENT}

This work is supported by The zhuhai college of jilin university innovation ability cultivating engineering projects " Research on the green design of garment in the sustainable development "(2015KYSKXJ039) and the project consists of Zhuhai College of Jilin University teaching quality project provincial project "Baoli Garment Co. Ltd. of art department internship teaching base" (ZLGC20130203).

\section{REFERENCES}

[1] Zhou Wenjie. The Design of Men's Wear. Zhejiang: Zhejiang People's Fine Arts Publishing House, 2005.

[2] Zhao Mingdong, Yuan Li. Breaking the Boundary of ThinkingInnovation and Manifestion of Clothing Design. Beijing: China Textile Press, 2005.

[3] Shen Lei, Wu Xiaoyi, Chen Puyin. The Change on the Role of LaceFrom Auxiliary Material to Main Material . Silk, 2012(11)

[4] Feng Lingling. Research on the Innovative Thinking in the Design of Men's Wear. Clothing Guide, 2014(02).

[5] Zha Weida. Analysis on the Application of Picture in the Design of Modern Men's Wear. Science and Technology, 2011(4).

[6] Zhou Yue. Discussion on the Cultivation of Innovative Thinking in the Teaching of Clothing Design. Journal of Nantong Textile Vocational Technology College, 2014(4). 